\title{
Comparison of nitrimidazine and metronidazole in the treatment of trichomonal vaginitis
}

\author{
J. S. MCCANN, J. D. H. MAHONY, AND J. R. W. HARRIS \\ Royal Victoria Hospital, Belfast, Northern Ireland
}

Until the introduction of metronidazole, the treatment of trichomonal vaginitis presented a considerable therapeutic problem. Local treatment was commonly followed by recurrence of the condition, doubtless partly because vaginal treatment alone failed to eliminate all foci of infection. Moreover, it became apparent that trichomonal infection was also often present in the male (Watt and Jennison, 1960; Catterall and Nicol, 1960) and no effective treatment in the male was available. The introduction of metronidazole by Durel, Roiron, Siboulet, and Borel (1959), however, resulted in a dramatic change, with a high percentage of both men and women responding rapidly to treatment with the drug (Rodin, King, Nicol, and Barrow, 1960). That metronidazole was not effective in all cases, however, soon became apparent (Rodin, King, Nicol, and Barrow, 1960; Willcox, 1960), and the search continued for a compound that would give even more effective results. In 1969, a new synthetic compound derived from nitro-imidazole, nitrimidazine, was introduced for the treatment of trichomoniasis (Emanueli and de Carneri, 1969). It was claimed that the trichomonicidal activity in blood serum samples taken from humans treated orally with $250 \mathrm{mg}$. doses of the new product was stronger and more rapid than with metronidazole (de Carneri, Cantone, Emanueli, Giraldi, Logemann, Meinardi, Monti, Nannini, Tosilini, and Vita, 1969). Moreover, whereas the metabolites of metronidazole were inactive, those of nitrimidazine were stated to retain part of their activity. Therapeutic action was thus provided not only by the drug itself but also by its principal metabolites (de Carneri and others, 1969).

Various claims for the therapeutic effectiveness of nitrimidazine have been made since its introduction. Emanueli and de Carneri (1969) reported an overall cure rate of 92.5 per cent. using different dosage regimens. With a dosage of $250 \mathrm{mg}$. twice daily for 6 days, Cohen (1971) stated that 62 of 63 women completing surveillance were cured. Moffett, McGill,
Schofield, and Masterton (1971), on the other hand, had an overall minimum failure rate of 16 per cent., 6.6 per cent. being regarded as 'primary' failures, while Evans and Catterall (1971) found the drug successful in only 68 per cent. of 57 patients.

The present investigation was carried out in the Department of Venereology, at the Royal Victoria Hospital, Belfast, to assess and compare the effectiveness of treatment with nitrimidazine and metronidazole.

\section{Material and methods}

100 female patients (Tables I and II) were treated with either nitrimidazine or metronidazole. Apart from three patients in whom the infection was resistant to the routine dosage of nitrimidazine and who were then given metronidazole in routine dosage, the patients were chosen at random for the treatment given, 48 receiving nitrimidazine and 52 metronidazole. The routine dosage was $250 \mathrm{mg}$. nitrimidazine twice daily for 6 days or $200 \mathrm{mg}$. metronidazole three times a day for 7 days.

TABLE I Age distribution (range 15 to 56 yrs)

\begin{tabular}{lc}
\hline Age $(y r s)$ & No. of patients \\
$15-16$ & 5 \\
$17-20$ & 24 \\
$21-25$ & 20 \\
$26-30$ & 23 \\
$31-40$ & 19 \\
$41-50$ & 6 \\
50 and over & 3 \\
\hline Total & 100 \\
\hline
\end{tabular}

TABLE II Marital status

\begin{tabular}{|c|c|}
\hline Status & No. of patients \\
\hline $\begin{array}{l}\text { Married } \\
\text { Single } \\
\text { Separated } \\
\text { Divorced } \\
\text { Widowed }\end{array}$ & $\begin{array}{r}32 \\
55 \\
11 \\
1 \\
1\end{array}$ \\
\hline Total & 100 \\
\hline
\end{tabular}


Each patient was examined clinically; diagnosis was based on the finding of the parasite by microscopy of the vaginal secretion, and on culture in Feinberg-Whittington medium. The patients were seen at frequent intervals during the first 2 weeks of treatment, and thereafter at weekly and then monthly intervals for 3 months or longer. Wet preparations from the vaginal secretions were examined microscopically at each visit, and cultures were taken as at the first examination.

Smears and culture for gonococci and Candida albicans were made at the same time, and serological investigations for syphilis were carried out as a routine; 74 additional sexually transmitted infections were found (Table III).

TABLE II I Numbers of patients suffering from other venereal diseases

\begin{tabular}{lll}
\hline Condition & & No. of patients \\
\cline { 1 - 1 } Gonorrhoea & 32 \\
Syphilis & $55^{\mathrm{a}}$ \\
Warts & 11 \\
Candidiasis & 3 \\
Scabies & \\
\hline a 1 Congenital & \\
1 Early latent & \\
1 Late latent & \\
2 Primary &
\end{tabular}

When possible the male consorts were treated simultaneously.

\section{Results}

The results of treatment are shown in Table IV.

TABLE IV Results of treatment with nitrimidazine and metronidazole

\begin{tabular}{|c|c|c|}
\hline Result & Nitrimidazine & Metronidazole \\
\hline $\begin{array}{l}\text { Cured } \\
\text { Primary failure } \\
\text { Secondary failure } \\
\text { aDefault cure? } \\
\text { Immediate default }\end{array}$ & $\begin{array}{r}23 \\
9 \\
1 \\
13 \\
2\end{array}$ & $\begin{array}{r}40 \\
5 \\
0 \\
4 \\
3\end{array}$ \\
\hline Total & 48 & 52 \\
\hline
\end{tabular}

aPatients who defaulted within 3 to 4 weeks but were trichomonas negative at the time of default.

Excluding the two immediate defaulters, 36 (approximately 78 per cent.) of the 46 patients treated with nitrimidazine had negative tests for the full period of follow-up or at the time of default. Ten (approximately 22 per cent.) were either primary (9) or secondary (1) failures. Of the nine primary failures, three were then treated with the routine dosage of metronidazole which also proved ineffective, but they subsequently responded to an increased dosage of metronidazole $(400 \mathrm{mg}$. three times a day for 7 days).
The corresponding figures for metronidazole (excluding the three defaulters) were 44 (approximately 90 per cent.) cured without later recurrences, and five (approximately 10 per cent.) primary failures. These five failures included the three who had failed to respond to nitrimidazine, and of the other two one responded subsequently to nitrimidazine $1 \mathrm{~g}$. followed by $500 \mathrm{mg}$. twice daily for 6 days. The second patient, who was given the same dosage, defaulted before the full period of follow-up, but gave a negative result at the time of default.

Six patients who failed to respond to both nitrimidazine and metronidazole were of special interest because they posed difficult problems regarding further management. The treatment and response were briefly as follows:

\section{Case 34/70}

This patient failed to respond to routine courses of both nitrimidazine and metronidazole. Subsequently a further course of nitrimidazine was given as $1 \mathrm{~g}$. stat. followed by $250 \mathrm{mg}$. three times a day for 7 days. After a period of negative tests, the Trichomonas was again isolated and the patient was treated with a combination of nitrimidazine and metronidazole, one tablet of each three times daily for 7 days, plus Pimafucin pessaries. She defaulted 4 weeks later but was trichomonas-negative at the time of default.

\section{Case 180/70}

Routine courses of both nitrimidazine and metronidazole were unsuccessful. Subsequently she was given a further routine course of metronidazole plus metronidazole tablets vaginally ( 1 twice daily for 10 days): this also failed. She was then given a course of S.V.C. pessaries (1 twice daily for 18 days) and the trichomonads disappeared. She was still trichomonas negative when discharged from observation at the end of 5 months.

\section{Case $70 / 68$}

This patient failed to respond to nitrimidazine, and also to nitrimidazine and metronidazole, 1 tablet of each three times a day for 7 days, plus Pimafucin pessaries. She responded finally to metronidazole tablets $400 \mathrm{mg}$. three times a day for 7 days plus 1 tablet vaginally twice daily for 14 days. She was still trichomonas-negative at the end of 2 months.

\section{Case 746/70}

Repeated courses of metronidazole and penotrane pessaries given elsewhere had been unsuccessful. She failed to respond to nitrimidazine tablets $250 \mathrm{mg}$. three times a day for 7 days, followed by a combined course of nitrimidazine and metronidazole (as in the previous case), and then to metronidazole tablets $400 \mathrm{mg}$. three times a dav for 7 days plus Pimafucin pessaries.

\section{Case 384/71}

This patient was not helped by routine courses of metronidazole and nitrimidazine, followed by metronidazole $400 \mathrm{mg}$ 
three times daily for 7 days and 1 tablet vaginally twice daily. This patient had a low I.Q. and may have been re-infected.

\section{Case 303/71}

This patient did not respond to repeated courses of both nitrimidazine and metronidazole separately and in combination and in varying dosages. She eventually defaulted.

In Cases $180 / 70,70 / 68$, and $746 / 70$, the contacts were also treated. Case $303 / 71$ was pregnant and living in a home for unmarried mothers, so that re-infection was unlikely. The baby was normal.

Case 746/70 complained of sleeplessness and anorexia whilst taking nitrimidazine; otherwise no toxic reactions were observed with either preparation.

\section{Discussion}

As other workers have noted, assessment of the final results is not easy, as there is always the possibility of re-infection in cases of recurrence, and no matter how carefully out-patients are chosen for a trial, there is no guarantee that the tablets will be taken as directed and the course completed. As mentioned earlier, as many male consorts as possible were treated with one or other drug, and among the cases of treatment failure no fewer than eleven consorts had received treatment. In all, 47 male consorts were treated, a figure rather lower than in the series reported by Cohen (1971), but higher than in that of Moffett and others (1971).

In our series, nitrimidazine did not appear to give such satisfactory results as metronidazole in the dosage recommended, though our results were better than those reported by Evans and Catterall (1971), and would appear to be more in line with those of Moffett and others (1971). Like Cohen (1971), we also found the clinical response to nitrimidazine to be rather slower than that to metronidazole.

The response to further treatment with both drugs was disappointing in cases of initial failure. Emanueli and de Carneri (1969) stated that nitrimidazine was also active topically, and reported a cure rate of 95.5 per cent. after the use of $250 \mathrm{mg}$. vaginal suppositories daily for 6 to 10 days. It is possible that some infections which resisted routine methods of treatment might have responded to this form of therapy. One of our patients (76/68) did finally respond to metronidazole tablets used both orally and as a pessary.

\section{Current investigation}

An investigation with nitrimidazine is now being carried out, giving a 2-day course of treatment consisting of five $250-\mathrm{mg}$. tablets as a first dose in the morning, followed by three $250-\mathrm{mg}$. tablets at night, the same dosage being repeated on the second day. Forty patients have been treated to date; seven defaulted immediately, leaving 33 patients for assessment.

Two treatment methods were adopted:

(1) The first dose of five tablets was administered in the clinic, and the second dose of three tablets was given to the patient with instructions to take them at bedtime. The patient was seen and reassessed the following morning and the same regimen was followed for the second day.

(2) If the patient was unable to attend on the second day, the first dose was taken in the clinic as before, and the remainder of the tablets were given with explicit instructions how they were to be taken.

25 patients were treated by the first method, and reassessment and follow-up were carried out as in the earlier investigation. Using the same classification as before, the results are given in Table V.

\section{TABLE $\mathrm{V}$ Results in forty patients in current trial}

\begin{tabular}{|c|c|}
\hline Result & Nitrimidazine \\
\hline $\begin{array}{l}\text { Cured } \\
\text { Primary failure } \\
\text { Secondary failure } \\
\text { aDefault cure? } \\
\text { Immediate default }\end{array}$ & $\begin{array}{r}17 \\
0 \\
1 \\
15 \\
7\end{array}$ \\
\hline Total & 40 \\
\hline
\end{tabular}

asee Table IV

The patient classed as a secondary failure was probably re-infected by her husband. She was trichomonas-negative after the first day's treatment but positive a few weeks later, and denied extramarital exposure. She was given a second course of treatment similar to the first and her husband, who had not been treated on the first occasion, was now treated similarly. She again became trichomonas-negative after the first day and remained so until she defaulted 2 months later.

Of the 25 patients in Group 1 (those seen on the second morning), all were already trichomonasnegative after the first day's dosage. Of those in Group 2, all were trichomonas-negative at the follow-up examinations. In spite of the negative findings in the 25 patients after the first day's treatment, a second day's treatment was given.

We have not yet attempted to give a one-day treatment only, but it is possible that this or indeed a single-dosage schedule may prove to be effective in the treatment of trichomoniasis.

Csonka (1971), using a single dosage schedule of 2 g. metronidazole (Flagyl) in 36 cases, had a cure 
rate of only 82 per cent., but the results in our present series would appear to be more impressive.

Apart from a few patients who complained of slight nausea or abdominal discomfort no unpleasant side-effects were noted.

\section{Summary}

Of 100 women with trichomoniasis, 48 were treated with nitrimidazine and 52 with metronidazole, the patients being chosen primarily on a random basis. Diagnosis was made by microscopy and culture in Feinberg-Whittington medium. The patients were followed-up for at least 3 months where possible. The dosage of nitrimidazine was $250 \mathrm{mg}$. twice daily for 6 days and of metronidazole $200 \mathrm{mg}$. three times daily for 7 days. 78 per cent. of the patients treated with nitrimidazine were either cured or had negative tests at the time of default; the corresponding figure for metronidazole was 90 per cent. 47 of their male consorts were also treated. Several patients failed to respond to both preparations and various combinations and dosages were tried with indifferent success. A current trial, employing a 2-day course with a dosage of five $250-\mathrm{mg}$. tablets of nitrimidazine in the morning and three $250-\mathrm{mg}$. tablets at night, is now being carried out, so far with highly encouraging results.

Our thanks are due to Carlo Erba (U.K.) Limited for supplies of nitrimidazine (Naxogin) and for their advice, interest, and help throughout the trial, and to our own clinic laboratory staff for their co-operation and help in the investigation.

\section{References}

Catterall, R. D., and Nicol, C. S. (1960) Brit. med. F., 1,1177

Cohen, L. (1971) Brit. F. vener. Dis., 47, 177

CsONKA, G. W. (1971) Ibid., 47, 456 de Carneri, I., Cantone, A., Emanueli, A., Giraldi, P. N., Logemann, W., Meinardi, G., Monti, G., Nannini, G., Tosilini, G., and Vita, G. (1969) 6th International Congress of Chemotherapy, Tokyo, August, 1969

Durel, P., Roiron, V., Siboulet, A., and Borel, L. J. (1959) C. R. Soc. franç. Gynec., 29, 36

EMANURLI, A., and DE CARNERI, I. (1969) 6th International Congress of Chemotherapy, Tokyo, August, 1969, and personal communication

Evans, B. A., and Catterall, R. D. (1971) Brit. med. F., 4, 146

Moffett, M., McGill, M. I., Schofield, C. B. S., and Masterton, G. (1971) Brit. F. vener. Dis., 47, 173

Rodin, P., King, A. J., Nicol, C. S., and Barrow, J. (1960) Ibid., 36, 147

Watt, L., and JenNison, R. F. (1960) Ibid., 36, 163

WILLCOX, R. R. (1960) Ibid., 36, 175

Comparaison de la nitrimidazine et du métronidazole dans le traitement de la vaginite à trichomonas

\section{SOMMAIRE}

Sur 100 femmes atteintes de trichomonase, choisies en principe par randomnisation, 48 furent traitées par la nitrimidazine, 52 par le métronidazole. Le diagnostic était fait par l'examen sur lame et par la culture sur milieu de Feinberg-Whittington. Les malades furent suivies pendant au moins trois mois chaque fois que ceci fut possible. La nitrimidazine fut donnée à la dose de $250 \mathrm{mg}, 2$ fois par jour pendant 6 jours et le métronidazole à $200 \mathrm{mg}$. 3 fois par jour pendant 7 jours. 78 pour cent des malades traitées par la nitrimidazine furent soit guéries soit négatives aux épreuves à la fin de l'observation; pour le métronidazole, le chiffre fut de 90 pour cent. 47 des partenaires masculins de ces malades furent également traités. Quelques malades ne répondirent à aucune des deux préparations et différentes associations ou posologies furent essayées sans que l'on puisse attribuer la guérison à l'une plutôt qu'à l'autre.

Un essai est actuellement en cours, utilisant un traitement de 2 jours à la posologie de cinq comprimés de $250 \mathrm{mg}$ de nitrimidazine le matin et de trois comprimés de $250 \mathrm{mg}$ le soir; jusqu'ici, les résultats sont très encourageants. 